\title{
Public Health, Socioeconomic Responses, and associated Challenges against Coronavirus Disease 2019 Pandemic in Nigeria
}

\author{
Idris Nasir Abdullahi ${ }^{1 *}$, Anthony Uchenna Emeribe ${ }^{2}$, Peter Elisha Ghamba ${ }^{3}$, Musa Sani ${ }^{4}$ \\ ${ }^{1}$ Department of Medical Laboratory Science, College of Medical Sciences, Ahmadu Bello University, Zaria, Nigeria; ${ }^{2}$ Department \\ of Medical Laboratory Science, University of Calabar, Calabar, Nigeria; ${ }^{3}$ WHO National Polio Reference Laboratory, University \\ of Maiduguri Teaching Hospital, Maiduguri, Nigeria; ${ }^{4}$ Nigerian University Pension Management Company, Abuja, Nigeria
} $\begin{aligned} & \text { Edited by: Mirko Spirosk } \\ & \text { Citation: Abdullahi IN, Emeribe AU, Ghamba PE, Sani M }\end{aligned}$ Public Health, Socioeconomic Responses, and Associate Challenges against Coronavirus Disease 2019 Pandemic in Nigeria. Open Access Maced J Med Sci. 2020 Aug 10 ; Keywords: Severe acute respiratory syndrom Keywords: Severe acute respiratory syndrom (ic health response; Socioeconomic challenges: Nigeri *Correspondence: Idris Nasir Abdullahi, Department of Medical Laboratory Science, Faculty of Allied Heath Sciences, Collge of Medical Sciences, Ahmadu Bello University, Zaria, Nigeria. E-mail: inabdullahi@abu.edu.ng Received: 12-May-2020 Revised: 01-Jul-2020 Copyright: ๑ 2020 Idris Nasir Abdullahi, Anthon Funding: Publication of this article was financilly Scientific Foundation SPIROSKI, Skopie, Republic of Macedoni Competing Interests: The authors have declared that no $\begin{aligned} & \text { competing interests exist } \\ & \text { Open Access: This is an open-access article distributed }\end{aligned}$ (CC BY-NC 4.0)

\begin{abstract}
For over 6 months of its emergence, the severe acute respiratory syndrome coronavirus 2 (SARS-CoV-2), the causative agent of coronavirus disease 2019 (COVID-19) pandemic, has resulted to unprecedented global health challenge and economic uncertainties. The pandemic swiftly disseminated to almost all the countries and territories of the world. The index case in Nigeria was imported by an Italian citizen on February 27, 2020. Typical of a novel respiratory tract viral infection, the spread of SARS-CoV-2 in Nigeria was slow in the first few days. However, as at 8:00 AM GMT+1, July 1, 2020, there were 25694 confirmed COVID-19 cases. With the continuous daily rise in the incidence of SARS-CoV-2 infection, enhanced surveillance programs were immediately activated and implemented in all parts of Nigeria. Even though an inadequate number of persons have been tested so far, the government of Nigeria has been activating public health laboratories to scale up its testing capacity. Due to the impact of partial lockdown and curfew in most states of Nigeria, the government has been able to provide some form of palliatives to vulnerable populations. This study aims to review and present the various public health and socioeconomic responses and challenges of the COVID19 pandemic in Nigeria. This reflects the efforts and successful steps taken to minimize the spread of COVID-19 in Nigeria.
\end{abstract}

\section{Introduction}

There are recent scientific controversies over the date and origin of severe acute respiratory syndrome coronavirus-2 (SARS-CoV-2), the etiological agent of coronavirus disease 2019 (COVID-19). It was initially widely believed to have originated from the Wuhan live animal market in Wuhan city, Hubei Province, China. However, recent reports are suggesting SARS-CoV-2 infection originated from laboratory recombination [1]. The first human-to-human transmission was reported to the World Health Organization (WHO) country office in China on December 31, 2019. But, SARS-CoV-2 was first imported to Nigeria through an Italian Citizen on February 27, 2020 [2].

Based on available data, the transmission dynamics of SARS-CoV-2 continue to improve with the evolution and expansion of the outbreak with time. Epidemiologically, the transmission of SARSCoV-2 can be broadly categorized into three stages, namely, from being asymptomatic to pre-symptomatic and symptomatic [3]; it is worthy to note that all these categories of people are infected with SARS-CoV-2 [3].
There are various mathematical models and biological investigations which seek to elucidate the transmission dynamics of SARS-CoV-2 [4]. At present, the only available means of controlling the spread of SARS-CoV-2 to previously uninfected locations is through consistent adherence to physical distancing, adequate hygienic practices, and monitored selfisolation of infected persons. Despite all these, the world continues rise in the incidence rates of SARS-CoV-2.

Initially, the spread of SARS-CoV-2 in Nigeria was slow with single digits, mainly at Lagos and Abuja, for 10 days (Figure 1) [5]. However, as at 8:00 AM GMT+1, July 1, 2020, 17 weeks after the first index case, there were 25693 confirmed COVID-19 cases with a case fatality rate of $2.3 \%$ [5]. Of these, Lagos ha the highest reported incidence and fatality rates (Table 1). Several observers have attributed the low reported incidence rate of COVID-19 in Nigeria and many African countries to be a cause of underdiagnosis probably because of inadequate molecular diagnostic capacity and few human resources skilled in molecular diagnostic tests [6]. Recently, a more worrisome in Nigeria is the mysterious and rise in the death rate of unknown origin in the ancient Kano city [7]. 
This study aims to review and present the various public health and socioeconomic responses and challenges of the COVID19 pandemic in Nigeria.

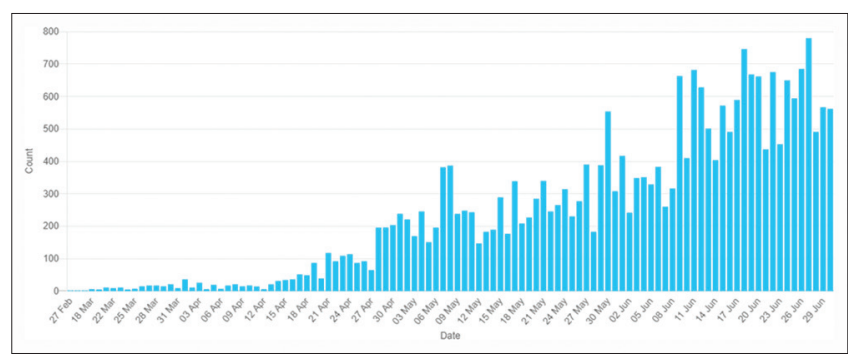

Figure 1: Daily trend of confirmed coronavirus disease 2019 cases in Nigeria [5]

This reflects the efforts and successful steps taken to minimize the spread of COVID-19 in Nigeria.

Table 1: Top 10 states with highest confirmed COVID-19 cases in Nigeria (as of July 1, 2020) [5]

\begin{tabular}{lllll}
\hline State & $\begin{array}{l}\text { Number of } \\
\text { confirmed cases }\end{array}$ & $\begin{array}{l}\text { Number of } \\
\text { death }\end{array}$ & $\begin{array}{l}\text { Number active } \\
\text { COVID-19 }\end{array}$ & $\begin{array}{l}\text { State } \\
\text { population }\end{array}$ \\
\hline Lagos & 10510 & 128 & 8779 & $12,550,598$ \\
$\begin{array}{l}\text { Federal capital } \\
\text { territory (Abuja) }\end{array}$ & 1870 & 33 & 1267 & $3,564,126$ \\
Oyo & 1380 & 12 & 672 & $7,840,864$ \\
Kano & 1216 & 52 & 233 & $13,076,892$ \\
Edo & 1105 & 39 & 778 & $4,235,595$ \\
Rivers & 1056 & 38 & 398 & $7,303,924$ \\
Delta & 965 & 23 & 752 & $5,663,362$ \\
Ogun & 826 & 19 & 238 & $5,217,716$ \\
Kaduna & 766 & 12 & 222 & $8,252,366$ \\
Katsina & 556 & 23 & 249 & $7,831,319$ \\
\hline CovID-19: Coronavirus disease 2019. & & &
\end{tabular}

\section{Public Health Response against the COVID- 19 Pandemic in Nigeria}

For about 7 days after the first index (imported) case, there were few infection control measures implemented in Nigeria [5]. However, the evolving nature and spread of the SARS-CoV-2 infection have led to a thorough rejig of initial control measures. Particularly, the geometric increase in new cases of COVID-19 has warranted the Federal Government (FG) to constitute a COVID-19 presidential task force saddled with the responsibilities of containing the spread of SARS-CoV-2 infection and other public health responses [5]. As SARS-COV-2 continued to spread to 35 states and Abuja (the federal capital territory) of Nigeria, a similar task force has been adopted in all state levels with a various state task force which has been constituted with representatives from the government executive arm and members of the health sector [8]. The FG of Nigeria issued public health advisories, which included an initial 2 weeks lockdown of 3 high-risk States, closure of land, and international air borders. In addition, the FG and several state governments (SGs) have put in place other measures such as the opening of isolation centers, inter-state border closure, movement restrictions, and stay-at-home policy to ensure full compliance of physical distancing [5]. Recently, the FG encourages the use of locallymade Personal Protective Equipment (such as face masks), continuous monitoring of institutions that offer essential services to ensure that they maintain a restricted number of guests within their premises and also strategically position temperature devices as well as water and soap for hand hygiene, and the temporary ban on the traditional crowded funerals, religious, weddings, and other social functions [5].

Even though there are over 206 million Nigerians, as of July 1,2020 , the Nigerian Center for Disease Control (NCDC) had only been able to test about 1,34,257 persons across its 37 testing sites [5]. In the past 4 weeks, more efforts such as activation of more laboratories and isolation centers were undertaken by the $\mathrm{FG}$ due to the sudden and persistent double-digits reports of new cases of COVID-19 in certain states, which suggested active community transmission. Hence, Abuja and Lagos had embarked on active community case search and testing. This public health response has led to the detection of more asymptomatic cases at the community level.

There is an ongoing plan by the NCDC to activate $\geq 1$ COVID-19 testing center(s) in every State of Nigeria to optimize early case detection, especially in rural and remote settlements [5]. Furthermore, Nigeria plans to adopted house-to-house testing to meet up with the National testing goal. It will enable prompt case detection isolation and avoid further transmission of SARS-CoV-2 infection. As a measure to minimize contraction of SARS-CoV-2 infection, the FG has massively advocated for periodic environmental disinfection exercises be conducted in every community.

At present, a major factor that could facilitate the spread of SARS-CoV-2 infection Nigeria is the densely populated camps of internal displace persons that experienced terrorism crises in the Northeastern part of Nigeria [9]. In these camps, the practice of physical distancing and other infection control and prevention measures cannot be guaranteed [10], [11].

\section{Socioeconomic Impacts and Response to the COVID-19 Pandemic in Nigeria}

In view of the hardship and adverse effects due to COVID-19 pandemic on household and home economy, FG and various SGs have begun houseto-house distribution of palliatives in the form of cash transfer and foodstuffs covering urban, semi-urban, and rural residents. However, the selection of eligible citizens was proposed to be based on either having a maximum of 15 US\$ (5000 Nigerian Naira) in the bank account and/or maximum airtime expenditures of 0.3 
US\$ (100 Nigerian Naira) [12]. In addition, FG and some private organizations have made available interest free or very minimal interest-based loans to small-and middle-income enterprises. The later was severely affected by the COVID-19 pandemic (especially the agricultural sector).

Due to the insufficient molecular testing centers, it is necessary SGs provide the enabling environment for epidemiologists, NCDC staff, and appropriate health-care professionals to promptly collect and test samples from suspected cases. Besides, FG and SGs should expand and activate as many laboratories, isolation centers, and COVID-19 frontline workforce. However, not every state has a designated COVID-19 testing laboratory. Even though the FG and some SGs made an upward review of hazard and risk allowances, there is an urgent need to implement health and/or life insurance cover for all frontline healthcare workers. It has become necessary due to the recent report of the rising number of HCWs infected by SARS-CoV-2 from 40 to 113 in 1 week [13].

A major socioeconomic factor which could affect the COVID-19 response in Nigeria is the high level of poverty among infection vulnerable population, especially in crises zones [9]. These humanitarian crises affected persons experience various grades of malnutrition, increase risks of communicable and non-communicable diseases [14]. These may weaken their innate immunity and make them have chances of contracting severe COVID-19 [15].

Despite the palliatives distributed to the vulnerable populations, the reality on the ground is that only a small fraction of the population confirmed to receive the support [16]. Unfortunately, the majority of Nigerian citizens have disobeyed the lockdown order with the plan and hope of earning some money through petty trades and services [16].

\section{Conclusion}

Evidently, there is a widespread ongoing community transmission of SARS-CoV-2. Hence, there is an urgent need to scale up testing capacity in Nigeria. Due to the impact of COVID-19 on the global economy, there might be a scarcity of COVID19 medical equipment and consumables, such as test kits and reagents. Hence, it is recommended that Nigeria and other African countries urgently consider production, evaluation, and validation of SARS-CoV-2 primers and rapid test kits to augment their stockpile. In consideration of the recent report that demonstrated the viability of SARS-CoV-2 in aerosol and fomites [17] and its ability to withstand high temperature [18], people must be restricted from risks of contracting SARSCoV-2 infection.

\section{References}

1. Hao P, Zhong W, Song S, Fan S, Li X. Is SARS-CoV-2 originated from laboratory? A rebuttal to the claim of formation via laboratory recombination. Emerg Microbes Infect. 2020;9(1):545-7. https:// doi.org/10.1080/22221751.2020.1738279

PMid:32148173

2. Nigerian Center for Disease Control. First Case of Corona Virus Disease Confirmed in Nigeria. Available from: https://www.ncdc. gov.ng/news/227/first-case-of-corona-virus-disease-confirmedin-nigeria. [Last accessed on 2020 Jul 01]

3. World Health Organization. Coronavirus Disease 2019 (COVID-19) Situation Report, No. 73. Available from: https://www.who.int/docs/ default-source/coronaviruse/situation-reports/20200402-sitrep-73covid-19.pdf?sfvrsn=5ae25bc7_2. [Last accessed on 2020 Jul 01].

4. Prompetchara E, Ketloy C, Palaga T. Immune responses in COVID-19 and potential vaccines: Lessons learned from SARS and MERS epidemic. Asian Pac J Allergy Immunol. 2020;38(1):1-9. https://doi.org/10.12932/ap-200220-0772 PMid:32105090

5. Nigerian Center for Disease Control (2020) COVID-19 Situation Report Situation Report, No. 52. Available from: https://www.ncdc.gov.ng/themes/common/files/sitreps/ c7c73f429bbda476f1419011e1a10403.pdf. [Last accessed on 2020 Jul 01].

6. Adepoju P. Africa's struggle with inadequate COVID-19 testing. Lancet Microbe. 2020;1(1):e12. https://doi.org/10.1016/ s2666-5247(20)30014-8

7. Voice of Nigeria. Kano Investigates Alleged Mass Death in the State. Available from: https://www.von.gov.ng/kanoinvestigates-alleged-mass-death-in-the-state. [Last accessed on 2020 Apr 21].

8. Ebenso B, Otu A. Can Nigeria contain the COVID-19 outbreak using lessons from recent epidemics? Lancet Glob Health. 2020;8(6):e7702020

PMid:32171055

9. Tijjani SJ, Ma L. Is Nigeria prepared and ready to respond to the COVID-19 pandemic in its conflictaffected northeastern states? Int J Equity Health 2020;19:77.

10. Global Humanitarian Response Plan for COVID-19; 2020. Available from: https://www.humanitarianresponse.info/sites/ www.humanitarianresponse.info/files/documents/files/global_ humanitarian_response_plan_covid-19.pdf. [Last accessed on 2020 Jul 1]

11. Poole DN, Escudero DJ, Gostin LO, Leblang D, Talbot EA. Responding to the COVID-19 pandemic in complex humanitarian crises. Int J Equity Health. 2020;19(1):41

12. Federal Government of Nigeria. Palliatives are for those with Less than N5,000 Bank Account. Available from: https://www. dailytrust.com.ng/palliatives-are-for-those-with-less-thann5000-bank-account-fg.html. [Last accessed on 2020 Apr 02]

13. COVID-19: Infected Health Workers Rise from 40 to 113 in One Week. Available from: https://www.punchng.com/covid-19infected-health-workers-rise-from-40-to-113-in-one-week. [Last accessed on 2020 May 02]

14. Unah L. "Nigeria will Deal with this": High Alert after Coronavirus Case; 2020. Available from: https://www. aljazeera.com/news/2020/03/deal-high-alertcoronaviruscase-200301140838366.html. [Last accessed on 2020 Apr 03].

15. World Health Organization. COVID-19 Immunity and Clinical Manifestations. Available from: https://www.who.int/docs/ default-source/coronaviruse/risk-comms-updates/update-24immuniy-n-clinical-manifestations.pdf?sfvrsn=7c84a6bf_4. [Last accessed on $2020 \mathrm{Jul}$ 21].

16. Kalu B. COVID-19 in Nigeria: A disease of hunger. Lancet 
Respir Med. 2020;8(6):556-7.

\section{PMid:32359414}

17. Doremalen VN, Bushmaker T, Morris D, Holbrook $M$, Gamble A, Williamson B, et al. Aerosol and surface stability of HCoV-19 (SARS-CoV-2) compared to SARSCoV-1. New Eng J Med. 2020;383(16):1564-7. https://doi. org/10.1101/2020.03.09.20033217
PMid:32182409

18. Luo C, Yao L, Zhang L, Yao M, Chen X, Wang Q, et al. Possible transmission osevere acute respiratory syndrome coronavirus 2 (SARS-CoV-2) in a public bath center in Huai'an, Jiangsu Province, China. JAMA Netw Open. 2020;3(3):e204583. https:// doi.org/10.1001/jamanetworkopen.2020.4583

PMid:32227177 